\title{
Towards the Development of Communicative Language Approach for Adult EFL Students of the Community College, Taif University, KSA
}

\author{
Abdulamir Alamin ${ }^{1} \&$ Sawsan Ahmed ${ }^{1}$ \\ ${ }^{1}$ Foreign Languages Department, College of Arts, Taif University, Taif, KSA \\ Correspondence: Abdulamir Alamin, Foreign Languages Department, College of Arts, Taif University, Taif, KSA. \\ E-mail: alamin@tu.edu.sa
}

Received: February 24, 2012 Accepted: September 7, 2012 Online Published: December 12, 2012

doi:10.5539/elt.v6n1p20 URL: http://dx.doi.org/10.5539/elt.v6n1p20

\begin{abstract}
The paper describes the experience of the author as a teacher in general English language skills program. In this paper an attempt will be made to briefly deal with the notion of communication, communicative language teaching, and its implications for teaching English as a foreign language students through language skills post-secondary program. Firstly, this paper aims to describe the problems that the students tend to have in these multi-level classes regardless of the difference in their age and sex. Suggestions will be given as how the teachers in these classrooms can do better to improve the students' performance. Then, it will suggest some strategies to successfully 'teach' these students, given the fact that all have different language skills that need to be improved. To achieve this goal, we shall look at the teaching process and suggest some ways to improve the teaching quality and students' learning and motivation.
\end{abstract}

Keywords: English as a second or foreign language, communicative competence, communicative approach, language acquisition

\section{Literature Review}

Under the inspiration of structural view to language description and Chomskean notion of competence, the language skill of a learner was considered as a set of grammatical instructions that students have to control a competent language user. However, the appearance of communicative account of language followed by the communicative approach to language teaching, the development changed and language aptitude gained new scopes. In order to be called a capable language student, the learners, besides grammatical competence, has to possess other skills such speech, sociolinguistic, and planned competencies (Freeman, 2000).

Communication, as well-defined by crystal (2001), is the discussion of ideas and facts between two or more individuals. A communicative structure consists, at least, three components, a dispatcher's information, and then is encoded in the nervous and muscular system. The communication leaves the despatcher and is conveyed via air in a spoken manner or in a written manner to the brain of the receiver via ear and eye where it is interpreted and converted into notions (Clark and Clark, 1977).

S.D. Krashen (1981) approached theory of "language acquisition", in which a learner with the mastery of his mother language learns another language without its social environment. According to the second language acquisition theory proposed by Krashen, understandable language input is the key to language acquisition. That is to say, learners mainly learn one language in two channels: one is acquisition and the other is learning. The former means that a learner takes in and then uses a language unconsciously through language communication practice while the latter means that a conscious study and understanding of a language.

Wells (1999) defined class interaction as a collaborative activity among language input, language information acceptance and language environment, which shows the importance of language acquisition environment and learners' internal encouragement system.

According to the theory of language internal syllabus, language learners' acquisition process should be gradual. Since the language acquisition effect will be influenced by the learners' intelligence, personality, learning motivation, interest and so on, language learning is a progressive, internal and natural acquisition process.

A variety of factors may influence second language acquisition, including teaching materials, syllabus, teaching methods, differences in personality, learners' motivation, attitudes as well as intelligence on language 
acquisition.

In Ellis' theory, a successful language learner will be able to adjust his strategies to his own cognition style and learning strategies. Students will try to seize every opportunity to practice and relieve his depression, hence achieving better efficiency and result. Personality influences the choice of language learning strategies. Teachers should find out students 'differences in personality, establish and perfect different teaching targets based and take specific measures for different students (Ellis, 1994).

Emotional factors influence the result of second language acquisition. Learning motivation is a strong internal drive for language learning and with attitudes they are closely associated with language learning strategies. Teachers should encourage students to have more creative thinking in order to develop their internal potentials, stimulate their diversified language learning motivation finally. A pleasant, natural and harmonious language learning environment has to come in planning of the teaching contents, teaching methods, teaching organization and teaching supervision. Teachers put excessive importance on the cognitive factors of second language learning while neglecting the role of emotional factors, learners have no way to release their emotions and express their feelings, resulting in the separation of cognition from emotion in English teaching.

Intellectual factors influence learners' achievements in second language acquisition. Memory ability, imitation ability, analysis and judgment ability as well as a potential ability for language learning are all important to develop students' intelligence, expand their views, develop their potentials and improve their cognitive abilities.

Second language theories suggest that the nature of language input, learners' acquisition process as well the rules of language acquisition should be taken into consideration when establishing teaching plans in order to set up a student-centered language learning pattern and to design specific class activities and teaching skills.

According to language acquisition principles, varieties of teaching methods can be used. The indirect method can be adopted. Henceforth, objects, gestures, expressions as well as actions can be used to enrich language learning environment. Listening-speaking method can be used where simulation, response, imitation and real -life listening and speaking practice will enable students to listen and imitate to learn pure pronunciation and intonation. The audio-visual method or the situational method is another method in which more importance is attached to language acquisition rules, a large amount of language input, the creation of teaching situation as well as the importance of vision in language learning. Finally, the communicative method can also be used where more emphasis on oral practice, employing real and natural language, cultivating students' communicative abilities to a natural process of language acquisition will take place.

Without any doubt, proper and flexible English teaching methods help to create language environment, to stimulate, students to take an active part in communicative activities so as to expand their language input methods and channels and improve their language acquisition efficiency.

Ellis R. (1994) pointed out that the failure to provide with opportunities to communicate naturally will separate learners from the main channel to gain language materials and hence to hold up the acquisition process. Language learning is a systematic process involving teachers, students and teaching materials.

In a word, second language acquisition research and English teaching are complementary to each other. Therefore, based on second language acquisition theories, teachers should establish necessary and real environment for students by speaking the target language at class, creating role-play activities based on specific situations, organizing and instructing students' group discussion and debates, hence promoting students' cooperative learning, providing a pleasant language acquisition environment, relieving students' anxiety and improving their success rate in language acquisition (Goodluck, 2014).

\section{The Paid Diploma of English as Foreign Language (PDEFL)}

PDEFL is a program funded by the government and Department of Social Assistance of the Ministry of Social Affairs. It is administered by the Foreign Languages Department at Taif University and offered by the Community College of Continuing Education. The main goal of this program is to assist students, males and females, with poor level of English proficiency to find employment and improve their English proficiency. Most of the students are funded throughout this program to learn English over a period of 780 hours during the period of 2 years, divided into 4 semesters of 15 weeks each with 195 hours each. The text books required for this program are "Interactions I and II", Listening, Speaking, Reading, Writing and Grammar. Computer skills class is also included. As far as the evaluation is concerned, one assessment test is given during the semester and one final test at the end of each semester. These assessment tests have to comply with the objectives set by Foreign Languages Department of the College of Arts of the University. In these English classes, students come from different social and educational backgrounds. The class, male and female students are taught separately. There 
are 30 students in the class. The reason why it is called "Paid Diploma of English as Foreign Language" is to differentiate this program from other diploma classes which are accredited and the study-plan is completely different.

\subsection{What is the Nature of PDEFL Class?}

The (paid) English diploma classroom consists of multi-levels of learning. In these multi-level ESL class, the following types of students are present:

a) students with no or little listening, reading, writing or speaking skills in English language;

b) students who preferred one skill to another;

c) students with diverse writing skills;

d) students with very different inspirations and educational schoolings.

In the PDEFLP classes, students can be good at particular or different skills. That is to say, one student may be very good at the speaking skill but may not in grammar. Besides, some students are not updated and the result is the existence of students with different levels of ability in one session. Apart from the fact that students begin the class with different levels of skill, they also advance in different steps of knowledge. Because they come from different school trainings, they often have different learning tactics, learning performances, learning objects and anticipation. Because of these features, the value of teaching and learning in a multi-level ESL class can be affected by many influences, such as speed of learning, sex issues, social issues, or learning styles, or learning incapacities

There is an enormous inconsistency in the language ability altitudes of the students, students are admitted to the class at the beginning of the semester regardless of their secondary school average. There are always students at different ability level in the same class. The variance is also broadened by the fact that each learner has different skills that need to be improved in each 195-hour semester.

\subsection{Advantages and Disadvantages of the PDEFL Classes}

Although the PDEFL is a multi-level class, nonetheless, such classes have some advantages:

- Students can use their skills to help each other.

- Teachers can modify their teaching strategies to provide more lessons activities that can improve students' teaching skills.

- Competition among students is lessened. Students in these ESL classes often accept that each student is at different levels of learning.

- Students absorb the fact that they have to be responsible for their own learning strategies and learning behaviours.

In reality, these multi-level ESL classes show more disadvantages than advantages, which are very inspiring to ESL teachers. These difficulties are:

- Students of lesser levels may feel helpless, left out and angry.

- Students of advanced levels may feel uninterested and discouraged.

- Teachers have to do more work for class supervision and instruction material training. The consequence is often more planning which is often timewasting and exhausting.

- It is hard to use the same source of instruction resources.

- There is fewer period for each group of students.

\subsection{Certificate in English as a Foreign Language}

The Certificate of the PDEFL provides a setting for students of English in Saudi Arabia to mature the language and learning abilities required to:

- Start additional education and training.

- Pursue and retain employment.

- Contribute in the community service.

The syllabuses for PDEFL differ from traditional language syllabuses in that language is not symbolized merely as syntactic forms; rather it is seen as a source for construction meaning sense. 
Using language includes selecting from structures of text structure in the form of writing, grammar, vocabulary in the practice of reading, listening, speaking, and computer skills. Learning language, therefore, contains learning to choose from these systems in ways that allow the students to connect successfully in a variety of context.

The Diploma Certificate in language skills aims to provide a mutual unconventional language for describing the characteristics of students and course provision. They are not accredited, but academically registered and meet the ethics of the Quality and Accreditation Assurance of education institute. Criterion-referenced assessment is used to assess learner accomplishment.

This program supports explicit and systematic teaching practice and they can be delivered through face-to-face teaching and by distance and e-learning approaches.

\subsection{The Teaching Materials of the PDEFL}

The textbooks used were "Interactions series 1 and 2". This is the afresh extended five-level, four-skill comprehensive ESL/ELT series from beginners to advanced learners. Those books integrate interactive and communicative activities while still concentrating on skill building. Reading, writing, listening and speaking, as well as grammar are methodically offered in separate books. Listening/Speaking opportunity includes listening strategies, listening skills, language functions and speaking tasks. Reading comprehension setting the context activities introduce main vocabulary and acquaint students with the chapter theme; opening activities include model talks, readings, class talk, expectation activities, previewing, and pair dialogues; conversation questions emphasize students' accepting of the themes through understanding questions and reassure students to express themselves; Pair work Activities inspire students to identify and exercise conversation in the target language; The Grammar setting provide clear, easy-to-understand, and visually attractive grammar expositions; "Using What You've Learned" component in the book delivers opportunities to do the writing exercises in the writing textbook. The computer course is a basic acquaintance and training of the computer skills.

\section{Methodology}

Two questionnaires are used in this study. One for the instructors which covers six areas of interest to the programme: course organization; assignments; examinations and grading; instructor and student interaction; methods of teaching; students learning outcome; textbooks and resources. The students' questionnaire covers 26 items which is a survey of their opinion about the program (see appendixes A and B).

\section{Discussion}

The existing students are secondary school graduates who have graduated within the last five years. Some of them are fascinated to join the university when they meet the requirements and pass the admission tests of the concerned departments, others are just undecided. But there is a good portion of those students who are looking to progress their profession for a better job or seeking a new one. All students are getting free tuition and allowance monthly. Nevertheless, there is a lack of motivation and more often, these classes are often considered as not "desirable". However, given the fact that these classes still running at least one more year until they finish the program, yet for the future programs, and after reviewing the results of the survey questionnaires of the instructors and the students, which show general satisfaction on the both sides, the students and the instructors.

Nevertheless, the following strategies are suggested to improve the classroom situation and involve the students in the best probable techniques, The results of the instructors' survey have shown that most of the 12 male and female instructors agree to give "agree", to most of the items of the questionnaire except few remarks regarding the use of the language laboratories in listening and speaking skills and to increase the hours of teaching for the program in general. They found some level of difficulties to some of the students, both male and female, which this might lead to asking for more screening of the students in enrolling in the programme.

The instructors helped the students to understand the questions of the questionnaire. They translated it to Arabic. Students', more than 25 of them answered in favour of their instructors, Students found them well prepared and willing to answer their questions and enthusiastic in teaching. Students did not write any negative comments about their instructors. The only major complain was about the lack of the use of the language laboratories. They attended regularly to the classes except a few absences due to conditions of work.

\section{Suggestions to Improve Students' Learning, Teaching Methods and Approaches in the PDEFL}

These are the findings of the students' questionnaire:

1. In answering the questions regarding "grammar aspect", (Item14, of students' questionnaire), majority of students support more listening and speaking activities in the class to avoid concentrating on grammar rules. 
These activity drills can be incorporated in the class along with the materials presented in the textbook. Some students suggested some games that the students will enjoy and suit the culture and students' age and needs. One of these games is guessing the word. In such a game, the teacher describes a show or character related to that category without being too obvious or too ambiguous. The students must try to guess the correct answer. In other words, play a guessing game in which students have to guess the meaning of a word from set of signs.

2. Another activity came in answering to items 12 and 13 regarding the listening and speaking textbooks, students asked for more class participation and exercises which can be incorporated in the class and along with the teaching of the textbook. An example was given is to play a game where students can communicate and negotiate in which students can buy or sell, negotiate or bargain, etc. The teacher is to pick any game (board games or card games) that comes with guidelines. If not the teacher could make his own instructions. The idea of the activity is to have the students read and comprehend for themselves what the instructions of the game are. Students will know the rules to certain games. Different rules could be made. Teachers can create groups of three or four learners provided that each one must feel happy in their own group.

3. Additional exercise activity in which students can be involved is reading. This came in answering to item 10 of the student's questionnaire. They suggested using maps or driving instructions, or fliers of famous superstores which could be beneficial in order to find pictorial material. This kind of exercise will help the students to find or locate visual information in their neighboring location or classroom (Vays \& Patel, 2009).

4. Exercises should be wisely selected and student must be properly tested. Questions 16 and 17 found adult ESL students are easily depressed. Students were saying the pace was "ok", but sometime for the sake of covering the designated materials for the term, instructor go faster and eventually students find the materials too hard for their existing level. For students of lesser levels, some writing exercises may make them feels helpless, left out and discouraged, (that was the answers to questions 15, 16, and 17). For other students, they feel uninterested and low if challenged with a very simple and easy exercise. Therefore, it is vital that educators should be prepared to embrace events that meet students' wishes and hopes (Wrigley \& Guth, 1992). Students' cultures cannot be ignored. Item 18, of the student's questionnaire asked the students if the class environment was perfect for teaching. They agreed collectively that it would be more effective if different groups of students in the same class were applicably challenged so they can be all involved in the lessons, at different levels according to their abilities (White, 2009).

It is not an easy job for the educator or teacher to produce an assignment with different levels of difficulties of different skill levels, but having a homogenous class is not an option with the PDEFL classes, and it is the only way to recover learning and teaching excellence in a multilevel ESL class. Teachers expressed their concern regarding assignments and projects in item 18. They suggested some project tasks according to the students' language levels, or the complexity of tasks or the amount of backing provided. Through the group actions, a good rapport among the students and between the students and the teacher can be established (White, 2009).

5. Research showed that students work better in a relaxed learning atmosphere. They do not like to work under pressure or to be continuously corrected, as this makes them feel inferior the class. This was obvious in their answers to items 7, 9, 16, 17, 18 19, and 20 of their questionnaire. Majority of students showed their reluctance to be encountered with questions in the classroom. This showed in their daily class participation. Adult students are very sensitive. If they feel being intimated or uncomfortable, they tend to withdraw and decline taking part in the task. It is very important that students do not feel the pressure to perform acceptably. As long as they like the learning practise and join willingly in the task, the activity will be considered fruitful (Brookfield, \& Holst, 2010). In a comforting atmosphere students do not feel vulnerable or reluctant. When the pressure is not there, students can interrelate and do better and can participate in the task easier (Varela, 2010).

6. Learning the language skills are the decisive objective of any learning situation but topics should be the attention of classes of this kind (Varela, 2010). Students and instructors did not find the textbooks, "Interactions 1 and 2", difficult or "not suitable" to their culture. Most of the students agreed that the course syllabuses; reading, writing, listening, speaking, and grammar, items 10-14), were clear and understandable for which all the instructors agreed (items 29-33). Mere control of grammatical skill never assures the learner's capability to know and comprehend language. In these PDEFL classes, most students often struggle with the idea of learning writing or speaking. They find it quite hard to recognize familiar terms to comprehend and understand or memorize grammatical rules of the language. This was clearly showed in answering questions 11 and 13. Half of the students "disagree". Topics and themes should be the key goal of any lesson. Consequently, the teacher's duty should monitor and lead the students to a firm topic related to their daily lives and culture, rather than concentrating on language rules. Instructors did not find any extra learning resources or adequate facilities for 
better teaching and learning outcomes. The topics instructors were looking for could be found in self-access resources which permit students to take initiatives to choose drills appropriate to their levels (Brindley, 2000).

6. Each class and each group should be given the time they need to finish an activity in the listening, speaking, reading, writing or the computer class. Students from another class or group will work to make their answers complete. This is the answer to item 7 of the students' questionnaire regarding the pace of teaching, items 10-15, regarding the difficulty level of the course. In other words, the same assignment will be given to all the students; however, each group will be given a different duty that is suitable to their level (Varela, 2010).

7. Students as well as instructors asked for more hours to cover the course objectives and learning outcomes. This can be done by taking the particular language course daily instead of each other day. The current timetable permits two hours for each skill weekly. Students will benefit more if they were given three hours from the beginning of the course.

8. Under recommendation, both students and instructors asked for better listening and speaking environments by letting them use the language laboratories for listening and speaking courses. Research shows that teaching and learning will be more effective if a language laboratory is used to teach those skills.

\section{Conclusion}

Students' and instructors' questionnaires were summarized to explore information about the course study-plan, aims and objectives, textbooks and teaching methods used in the Paid Diploma of English language as run by the Department of the Foreign Languages of the Faculty of Arts, Taif University. The implications of these findings are for implementing more effective learning and teaching strategy instruction. This paper has come with some strategies which can help teachers engage the students for better learning and teaching situation. ESL/EFL class is a challenging learning environment, it is crucial that teachers have excessive skillfulness and sensitivity to handle the class. It is hoped that this paper has provided some practical guidelines for the instructors to make group work as well as individual learning relaxed and more useful. Variable approaches in teaching the four language skills are indispensable to ensure a successful learning atmosphere. It is the duty of the educators to make a well-organized use of self-access learning material, whether it exists in the books or given as extra work, can provide benefit for further improvement. Even though the research findings are not conclusive in the relationship between personal factors and second language learning, teachers agreed that students" individual aptitudes, personalities, and learning styles should be taken into account to create a learning environment in which virtually all students can be successful in learning English language.

\section{References}

Brindley, G. (1989). Assessing Achievement in the Learner-Centred Curriculum. Sydney: National Centre for English teaching and Research, Macquarie University.

Brindley, G. (2000). Task difficulty and task generalizability in competency-based Writing Assessment. In Brindley, G. (Ed.), Studies in immigrant English language assessment (Vol. 1, pp. 125-158). Sydney: National Centre for English Teaching and Research, Macquarie University.

Brookfield, S., \& Holst. (2010). Radicalizing Learning: Adult Education for a Just World San Francisco. (Jossey-Bass. Higher Adult Education).

Burns, A., \& Hood, S. (eds.) (1995). Teachers' Voices: Exploring Course Design. Sydney: National Centre for English Teaching.

Christie, F. (1998). English Language and Literacy Placement Assessment Kit. Sydney: New South Wales Australian Migrant Education Services.

Christie, F. (Ed.) (1990). Literacy for a Changing World. Melbourne: Australian Council for Educational Research.

Clark, H. H., \& E. Clark. (1977). Psychology and Language. An introduction to psycholinguistics. New York: Harcourt Brace Jovanovich.

Crystal, D. (2001). A Dictionary of Language and Languages ( $2^{\text {nd }}$ ed.). Chicago: University of Chicago Press.

Ellis, R. (1994). Second Language Acquisition .Oxford: Oxford University Press.

Freeman, D. L. (2000). Teaching Techniques in English as a Second Language: Techniques and Principles in Language Teaching. New York. Oxford University Press.

Freeman, D. L., \& Anderson, M. (2011). Techniques and Principles in Language Teaching. New York: Oxford University Press. 
Goodluck, H. (2014). Language Acquisition. Somerset, New Jersey: Wiley-Blackwell.

Jackson, E. (1993). Non-Language Outcomes in the Language Classroom. Sydney: New South Wales Australian Migrant Education Services.

Joyce, H. (1992). Workplace Texts in the Language Classroom. Sydney: New South Wales Australian Migrant Education Services.

Krashen, S. (1981). Second Language Acquisition and Second Language Learning. Pergamon: Oxford University Press.

Varela, M. et al. (2010). Current Issues in English Language Teaching and Learning: an International Perspective. Cambridge: Cambridge Scholars Publishing.

Vyas, M., \& Patel, Y. (2009). Teaching English as a Second Language. New Delhi: PHI Learning.

Wells, G. (1999). Learning through Interaction. Cambridge: Cambridge University Press.

White, W. et al. (2009). From Teacher to Manager: Managing Language teaching. Cambridge: Cambridge University Press.

Wrigley, \& Guth. (1992). Bringing literacy to life: Issues and options in adult ESL literacy. Aguirre International for the U.S. Dept. of Education, San Mateo: CA: Aguirre International.

\section{Appendix A: Instructor's Survey}

Dear Instructor, this is a course evaluation survey for the Paid Diploma of the English Language. Write 1. Strongly Disagree 2- Disagree 3- Agree 4- Strongly Agree.

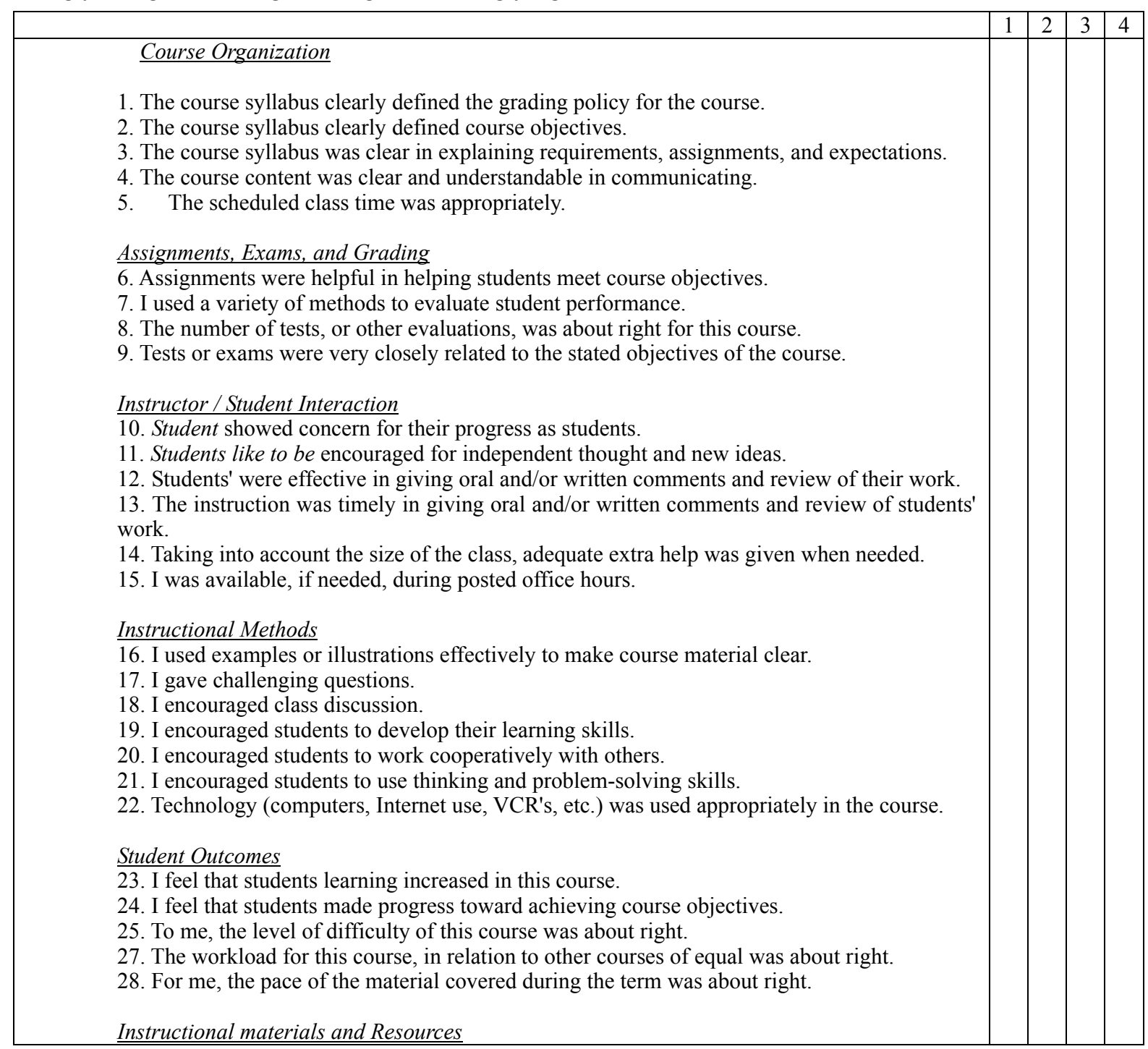


29. The textbook and/or course materials were useful tools for the course.

30 . The textbook and/or course materials were easy to understand.

31 . I encouraged students to use the Internet in completing some course work.

32. I made good use of the school's library and learning resources.

33. Classroom facilities and the learning environment were adequate for students learning experience.

Thank you for your cooperation.

\section{Appendix B: Student's Survey}

Course Name:

Instructor:

Please complete this course evaluation by assigning each statement a number which

corresponds to your opinion. Place an $\mathrm{X}$ in the column that corresponds to your choice.

I wish to get objective and anonymous responses from the class. By remaining anonymous, you can be honest and I can get a more accurate impression of how you feel about the course.

Rating system: 1- Agree strongly 2-Agree 3-Unsure 4-Disagree 5-Disagree strongly 6-Not applicable.

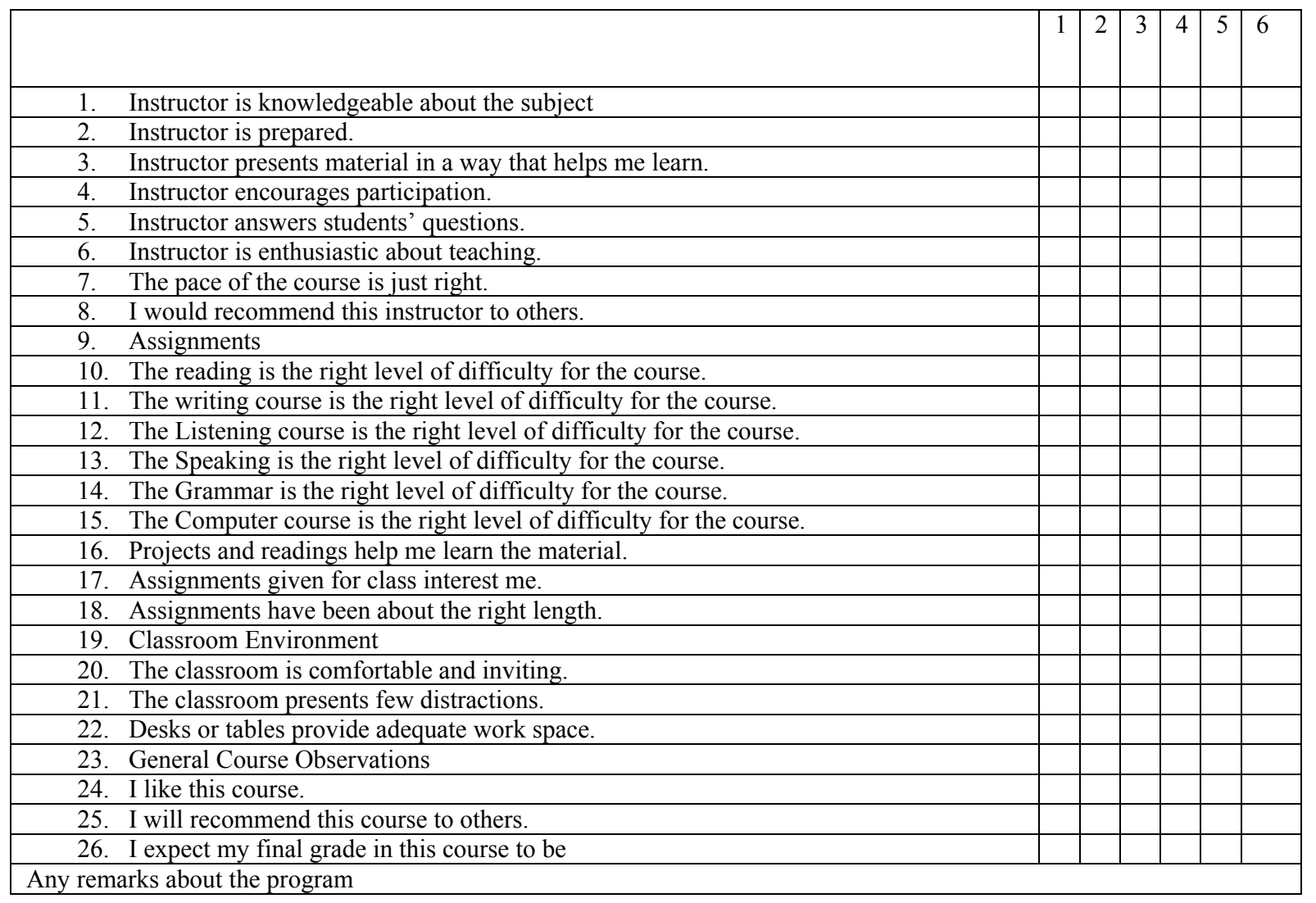

THANK YOU. 